\title{
The Informational Content of the Shape of Utility Functions: Financial Strategic Behavior
}

\author{
Joost M.E. Pennings $\mathrm{s}^{\mathrm{a}, \mathrm{b}, \mathrm{c}, \mathrm{d}, *}$ and Philip Garcia ${ }^{\mathrm{c}}$ \\ a Department of Finance, Maastricht University, Maastricht, The Netherlands \\ ${ }^{\mathrm{b}}$ Department of Marketing, Maastricht University, Maastricht, The Netherlands \\ ${ }^{\mathrm{c}}$ Office for Futures and Options Research, University of Illinois at Urbana-Champaign, Urbana, IL, USA \\ ${ }^{\mathrm{d}}$ Department of Marketing and Consumer Behaviour, Wageningen University, Wageningen, The Netherlands
}

\begin{abstract}
Recently, Pennings and Smidts (2003) showed a relationship between organizational behavior and the global shape of the utility function. Their results suggest that the shape of the utility function may be related to 'higher-order' decisions. This research examines the relationship between financial strategic decisions and the global shape of the utility function of real decision makers. We assess the shape of utility functions of portfolio managers and show that the global shape is related to their strategic asset allocation. The findings demonstrate the informational content of the shape of utility functions in the context of financial strategic behavior. Copyright (C) 2008 John Wiley \& Sons, Ltd.
\end{abstract}

\section{INTRODUCTION}

Utility is an important concept in economics and management sciences that has been used extensively to derive optimal behavior of decision makers and to describe observed behavior (Schoemaker, 1982). Most empirical studies have focused on the relationship between operational decisions and decision-makers' risk attitudes as measured by the curvature of the utility function (Pennings and Smidts, 2000). Recently, Pennings and Smidts (2003) explored the relationship between organizational behavior (production system employed) and the global shape of utility functions of real decision makers (hog farmers). Their results

\footnotetext{
*Correspondence to: Department of Finance, Maastricht University, Tongersestraat 53, Room B1.13, 6211 LM Maastricht, The Netherlands. E-mail: joost.pennings@finance. unimaas.nl
}

Copyright (C) 2008 John Wiley \& Sons, Ltd. suggest that the global shape of the utility function contains information that can help to predict and explain organizational behavior.

Strategic decisions are decisions that determine overall direction and organization of an enterprise and have far-reaching effects on its structure (e.g. Quinn et al., 1988). These decisions impact the whole outcome domain of the firm. Since the shape of the utility function takes the entire outcome domain into account (i.e. the total range of attribute $x$ ), we anticipate that its shape contains information that can be used to predict strategic decisions. Kahneman and Tversky (1979), Rabin (2000) and Pennings and Smidts (2003) argued that a local measure of utility may not be of great interest when trying to understand the behavior over a wide outcome range, which supports this notion.

We assess the utility functions of 104 portfolio decision makers who manage equity investments 
by making strategic asset allocations decisions. Various authors have examined the biases in utility elicitation (Hershey et al., 1982). The two most important biases are that subjects may not be real decision makers, and that utility is elicited in an unrealistic decision-making situation. Here, we measure the portfolio manager's utility function using a certainty equivalence elicitation procedure in a realistic decision context. Accounting data that contain information about managers' strategic behavior (e.g. whether or not they invest in non-exchange traded assets) complemented the experimental data. Following Pennings and Smidts (2003) we determine the shape of each portfolio manager's utility function using two different methods, thereby examining whether the results are method invariant. We show that the shape of decision-makers' utility functions predicts managers' asset allocation strategies. The results demonstrate the informational content of the shape of utility functions in the context of financial strategic behavior.

\section{THE SHAPE OF UTILITY FUNCTIONS AND STRATEGIC BEHAVIOR}

In the economics and management literature, concave utility functions have been associated with risk aversion and convex utility functions with risk-seeking behavior. Pratt (1964) and Arrow (1971) proposed a local measure of risk aversion for the utility function $U(x)$ as the negative ratio of the second to the first derivative, $-U^{\prime \prime}(x) / U^{\prime}(x)$. The curvature is a convenient measure for empirical researchers as it can be estimated in a single-parameter model. Often the negative exponential (Exp) function given by $u(x)=-e^{-c x}$ is used to represent a decisionmaker's utility. Modeling the curvature, $c$, of the function implies that risk aversion is constant over the total outcome range $x$.

Prospect theory indicates that the curvature of the utility function differs between gain and loss domains and hence decision-makers' risk attitudes may vary over the domain. Evidence for convex/ concave utility functions has been found in various studies including Fishburn and Kochenberger (1979), Budescu and Weiss (1987), Kuhberger et al. (1999) and Pennings and Smidts (2003).

Here, we investigate the relationship between the global shape of the utility function-its form over the total outcome range - and a specific type of behavior, strategic decision making. Managers face a variety of choices, including operational decisions that involve daily fine tuning of specific strategies and strategic decisions that involve less frequently made choices on how operations are organized to meet overall objectives. Strategic decisions are by definition broadly based and require an integrative view of a firm's options, activities, resource base and goals. We hypothesize that manager's strategic decisions are related to the shape of the utility function over the total outcome range as the global structure of manager's preferences may influence these broadly based, integrative decisions. By investigating how the global structure of preferences affects strategic decisions, the research extends earlier research by Kahneman and Tversky (1979) and Rabin (2000), who argue that local measures of preferences may not be of great interest when trying to explain behavior over a wide outcome range. Pennings and Smidts (2003) demonstrated that the shape of the utility function can have predictive power in determining organizational behavior. Their results are suggestive that the global shape may be related to 'higher-order' decisions (Ansoff, 1965; Eisenhardt and Zbaracki, 1992; Swenk, 1995).

\section{RESEARCH DESIGN}

The research design closely follows Pennings and Smidts (2003). We assess the utility functions of portfolio managers and relate them to their strategic decisions. To test the robustness of the empirical results, the shape of the utility functions is assessed by applying two different methods. We first describe the portfolio managers' decision context, the elicitation process, the consistency tests and the two methods used to determine the shape of the utility functions.

\section{Decision Context: Financial Strategic Decisions by Portfolio Managers}

To examine whether the shape of the utility function contains information that may predict strategic behavior, we need a context in which strategic choices can be observed and utility elicited from decision makers. Portfolio managers make important investment decisions on a regular 
basis, weighing and balancing risk and returns. A strategic decision that portfolio managers make is whether or not to invest in assets that are not traded on a central exchange. These assets, often referred to as 'bricks and mortar', are direct investments in commercial property or in private companies, and their trading characteristics differ dramatically from those associated with exchange traded investment tools such as bonds and stocks. While bonds and stocks can be easily bought and sold and price quotations are almost always available, non-exchange traded assets cannot be bought and sold immediately, price discovery is not transparent and information on the factors affecting prices is not always available. In addition, non-exchange traded assets have relatively high transaction costs as ownership may require management of the property.

The stock and futures exchange NYSE-Euronext provided us with the names of portfolio managers of large corporations who dealt with their firms' assets to meet retirement obligations and the names of private portfolio managers who managed their own portfolio or on behalf of others. Regardless of the scale of the portfolios managed, these managers are faced with the same basic decision of whether to invest in nonexchange traded assets. Portfolio managers were contacted, informed about the study and invited to participate. If they agreed, an appointment was made to conduct the elicitation experiments. A total of 104 managers participated.

\section{Elicitation of Utility Functions}

Utility was elicited using computer-guided interviews based on the certainty equivalence method that was customized to the relevant decision context (Keeney and Raiffa, 1979; Smidts, 1997). In the elicitation, certainty equivalents were obtained through choice-based matching (Keeney and Raiffa, 1979; Fischer et al., 1999). When designing the procedure we took into account the findings of research on the sources of bias in assessment procedures for utility (Farquhar, 1984; Harrison, 1986; Tversky et al., 1988; Kagel and Roth, 1995; Holt and Laury, 2002). The main sources of bias arise when the assessment does not match a subjects' real decision situation. Here the research design reflects relevant choices made by real decision makers (Smith, 1991). The certainty equivalence technique was formulated in terms of relatively high/low returns with a range of -5 to $+20 \%$, with a probability of 0.5 and a fixed return. In-depth interviews with 15 portfolio managers revealed that these boundaries reflected the managers' minimum and maximum expected returns. The certainty equivalents were developed iteratively.

The measurement procedure was computerized and took about 20 minutes. Seven points were assessed, corresponding to utilities of $0.125,0.250$, $0.375,0.500,0.625,0.750,0.875$ plus two consistency measurements on utilities 0.500 and 0.625 . When tested, the differences between the assessed certainty equivalents for the same utility levels were not significant ( $p>0.99$ (pair-wise test)) for both consistency measurements showing that respondents assessed the certainty equivalents in an internally consistent manner.

\section{Assessing the Shape of Decision-Makers' Global Utility Functions}

Based on previous studies two broad classes of shapes-fully concave or fully convex, and Sshaped (convex/concave) (e.g. Bell and Fishburn, 2000; LiCalzi and Sorato, 2006)—were used. Fully concave or convex utility functions have been widely applied in the economics literature. Evidence in support of fully concave or convex utility functions over the outcome domain has been found in various studies including Binswanger (1981, 1982) and Pennings and Smidts (2000). An S-shaped utility function has been suggested in prospect theory (Kahneman and Tversky, 1979). Recently, Trepel et al. (2005) outline a neural base for S-shaped utility functions.

We assess the shape of the utility function using two methods. In the first, the EXP-inverse power transformation (IPT) method, we fit observations for each decision maker (the nine assessed certainty equivalents) to both the negative EXP and to the log of the IPT function, the latter being an S-shaped function. The EXP function is fully concave or fully convex over the entire outcome domain. The EXP function is often used in empirical studies, as it meets the general conditions of acceptable utility functions, specified by Arrow (Tsiang, 1972). The IPT function does not restrict the location of the inflection point and offers wide variations in the degree of symmetry for a specific inflection point (Bewley and Fiebig, 1988; Meade and Islam, 1995). In the second, the two-piece 
utility function method, two EXP segments were fit, one for consequences above the reference point (gain domain) and the other for consequences below the reference point (loss domain).

In the two-piece method we used the manager's stated target return on their portfolio (the average return in our sample was $9.5 \%$ ) as a natural reference point to decompose the utility function. By estimating the EXP function for each segment, we obtain for each manager two parameters: $c_{g}$ for the gain domain and $c_{l}$ for the loss domain (recall that $c$ in the EXP function represents the PrattArrow coefficient of absolute risk aversion). These parameters allow us to describe the shape of the function as a combination of $c_{g}$ and $c_{l}$. We can classify decision makers based on four different shapes: $c_{l}>0$ and $c_{g}>0$ implying a concave utility function for both gains and losses; $c_{l}<0$ and $c_{g}<0$ implying a fully convex utility function; $c_{l}>0$ and $c_{g}<0$ implying a reversed S-shaped utility function, and $c_{l}<0$ and $c_{g}>0$ implying an S-shaped function.

There is an extensive body of literature that outlines the potential pitfalls of eliciting utility functions using certainty equivalent technique experiments (e.g. Harrison, 1986; Kagel and Roth, 1995; Holt and Laury, 2002). To test whether the elicitation technique suffered from potential biases we conducted an additional analysis. The parameter estimated by the S-shaped utility function (IPT-group) allows us to calculate the average point of inflection for the decision makers that best could be described by an S-shaped utility function. We used the manager's target return to statistically compare the point of inflection of manager $i$ with the target return for portfolio $i$. When tested, the differences between the point of inflection and the target return were not significant $(p>0.99$ (pairwise test)). The analysis supports the notion that the use of a realistic decision context permits the elicitation of valid utility functions (Smith, 1991).

\section{RESULTS}

First we describe the results for the estimates of the shape of the utility function for the EXP-IPT and the two-piece methods, and discuss the classifications of the decision makers. Subsequently, the relationship between the shape and strategic decisions is established.

Based on a pair-wise comparison of the meansquared errors, the functional form that best reflects each decision-maker's utility function is determined and decision makers are classified in the corresponding groups (fully convex/concave or S-shaped).

The results in Table 1 illustrate that one group consisted of managers whose utility function is best described by the EXP function (an EXPgroup; $n=53(51 \%))$, the other group consisted of managers whose function is best described by the S-shaped function (an IPT-group; $n=51(49 \%)$ ). Next, we examine the shape of the function using the two-piece method, allowing us to examine whether the results of the EXP-IPT method are robust.

The results for the two-piece method for managers (Table 2, left-hand column) indicate that $47.1 \%(n=49)$ have utility functions that are concave for both the loss and gain domain (i.e. $c_{l}>0$ and $c_{g}>0$ ), and hence are said to be risk averse over the total outcome domain. A smaller group of managers $(5.7 \% ; n=6)$ can be described as risk prone over the outcome domain (i.e. $c_{l}<0$ and $\left.c_{g}<0\right)$. Only a few managers $(6.7 \% ; n=7)$ show a reversed S-shaped function (i.e. $c_{l}>0$ and $\left.c_{g}<0\right)$, while $40.4 \%(n=42)$ exhibit an S-shaped function. This result confirms the findings of the EXP-IPT method that managers differ regarding the shape of their utility function.

\section{Validation of Methods to Determine the Shape of the Utility Function}

To determine whether the EXP-IPT and the twopiece methods identify similar shapes for decision makers, we compare the two methods.

The results in Table 2 illustrate that the classification of the utility functions is almost invariant to the method, providing evidence that the identification of the shape of the utility function is robust.

\section{Shape of Utility Functions and Strategic Decisions}

We examine whether the shape of the utility function is reflected in decision-makers' strategic behavior using the results of the EXP-IPT method to identify the shape of the utility function. We do not present the results based on the two-piece method that are similar.

The upper part of Table 3 illustrates that $44.2 \%$ of the managers invested only in exchange traded assets, while $55.8 \%$ invested also in assets not 
Table 1. Average Results of Exponential and IPT-utility Estimates for Individual Portfolio Managers

\begin{tabular}{|c|c|c|c|c|c|c|}
\hline \multirow[t]{3}{*}{ Parameter } & \multicolumn{3}{|c|}{ Exponential function } & \multicolumn{3}{|c|}{ IPT-function } \\
\hline & \multicolumn{3}{|l|}{$n=53$} & \multicolumn{3}{|l|}{$n=51$} \\
\hline & $a$ & $b$ & $c$ & $\alpha$ & $\beta$ & $\kappa$ \\
\hline Mean & -19.821 & 19.740 & -1.434 & -6.550 & 90.364 & 30.509 \\
\hline Median & -1.840 & 1.721 & 0.387 & -5.094 & 22.012 & 6.744 \\
\hline \multicolumn{7}{|l|}{ Fit indices } \\
\hline Mean MSE & 0.004 & & & 0.005 & & \\
\hline Median MSE & 0.004 & & & 0.003 & & \\
\hline Mean $R^{2}$ & 0.882 & & & 0.898 & & \\
\hline Median $R^{2}$ & 0.914 & & & 0.901 & & \\
\hline
\end{tabular}

See the Appendix for function specifications. MSE, mean-squared error (predicted versus observed certainty equivalents, scaled on a $0-1$ scale). $R^{2}$ is calculated by squaring the Pearson correlation between the actual values and the values predicted by the model.

Table 2. Correspondence in Classification of Portfolio Managers by the EXP-IPT and the Two-piece Utility Function Methods

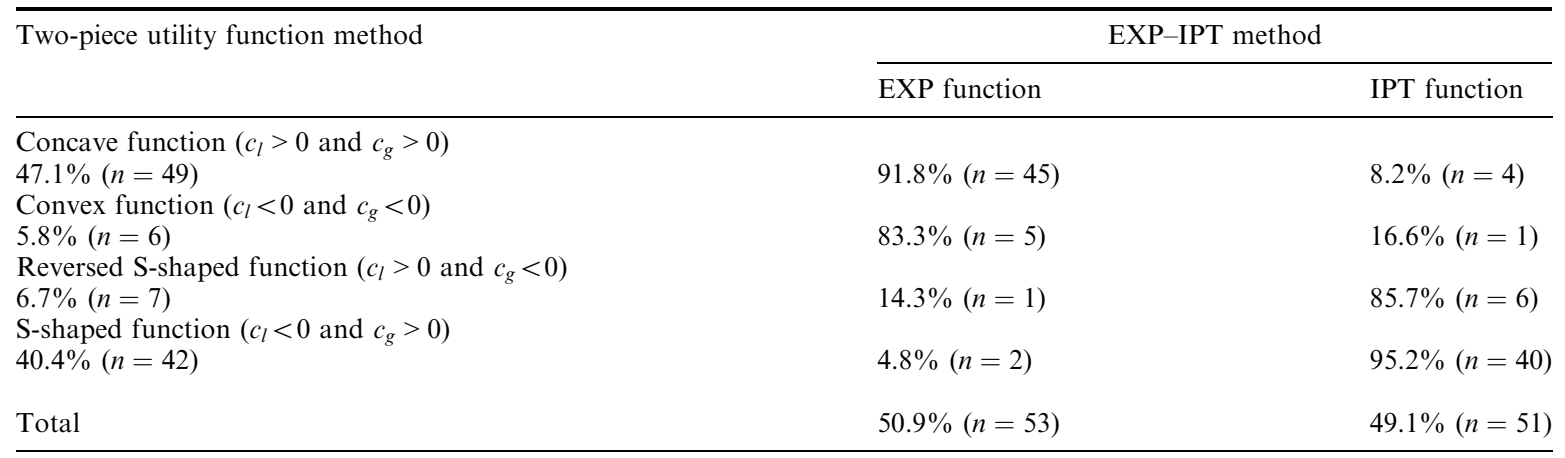

Table 3. Relationship Between the Shape of Utility Functions and Strategic Decisions

\begin{tabular}{llll}
\hline & $\begin{array}{l}\text { Invested only in } \\
\text { exchange traded assets (\%) }\end{array}$ & Invested in all assets (\%) & Total \\
\hline Total & 44.2 & 55.8 & $100 \%(n=104)$ \\
EXP-group & 17.0 & 83.0 & $100 \%(n=53)$ \\
IPT-group & 72.5 & 27.5 & $100 \%(n=51)$ \\
\hline
\end{tabular}

The EXP-group consists of managers whose utility function is described best by the exponential function (fully concave or fully convex). The IPT-group consists of managers whose utility function is described best by the log of the inverse power transformation function (see the Appendix for function specifications).

traded on an exchange. Of the managers with a concave or convex utility function (the EXPgroup), $17.0 \%$ invested only in exchange traded assets and $83.0 \%$ invested in all assets. In contrast, $72.5 \%$ of managers with an S-shaped utility function (the IPT-group) invested in only exchange traded assets, while $27.5 \%$ invested in nonexchange traded assets as well. These results indicate that managers whose shape of the utility function is best described by an EXP-type function (fully concave or fully convex over the total outcome range) have both exchange and nonexchange tradable assets in their portfolio, while managers whose shape of the utility function is best described by an IPT-type function (S-shaped utility function) invested only in exchange traded assets.

The results demonstrate that the shape of the utility function is related to financial strategic 
Table 4. Logistic Regression Results: Portfolio Managers' Strategic Decisions and the Shape of Their Utility Function

\begin{tabular}{lcc}
\hline & \multicolumn{2}{c}{ Trading in all assets $(=0)$ or trading in only exchange traded assets $(=1)$} \\
\cline { 2 - 3 } & $\beta$ & $p$ \\
\hline Shape of the utility function: & $-1.768^{*}$ & 0.04 \\
$(I P T=1 ; E X P=0)$ & 0.07 & 0.15 \\
Age & -1.53 & 0.15 \\
Education & 0.06 & 0.16 \\
Debt-to-asset ratio & & \\
Average value of portfolio for & 0.53 & 0.38 \\
which portfolio manager was & & 0.39 \\
responsible in 2000 & & 76.9 \\
Nagelkerke $R^{2}$ & & \\
Correctly classified choices $(\%)$ & & \\
\hline
\end{tabular}

The cut-off value for the misclassification is 0.500 . An asterisk indicates statistical significance $(p<0.05)$. Nagelkerke's $R^{2}$ is similar to the $R^{2}$ in linear regression and measures the proportion of variance of the dependent variable from its mean explained by the independent variables. The debt-to-asset ratio is measured on a 10 -point scale with $1=$ debt-to-asset ratio $1-9 \%, 2=10-19 \%$, etc. and the average value of the portfolio in Euros for which the manager was responsible was measured on a 8-point scale with $1<1$ million, $2=1-10$ million, $3=10-50$ million, $4=50-100$ million, $5=100-500$ million, $6=500$ million -1 billion, $7=1-5$ billion, $8 \geqslant 5$ billion.

Table 5. Relationship Between the Shape of Utility Functions and Managers' Corporate Environment

\begin{tabular}{llll}
\hline & $\begin{array}{l}\text { Fully concave/convex } \\
\text { function }(n=51)(\%)\end{array}$ & $\begin{array}{l}\text { S-shaped utility } \\
(n=53)(\%)\end{array}$ & function \\
\hline $\begin{array}{l}\text { Corporate environment } \\
\begin{array}{l}\text { Firms with known future fi- } \\
\text { nancial obligations }\end{array}\end{array}$ & 63.5 & 36.5 & $100 \%(n=53)$ \\
$\begin{array}{l}\text { Firms that do not } \\
\text { Total }\end{array}$ & 38.5 & 61.5 & $100 \%(n=51)$ \\
& 51.0 & 49.0 & $100 \%(n=104)$ \\
\hline
\end{tabular}

The category 'firms with known financial obligations' included insurance companies and pension funds.

behavior. To further gain insight into the predictive power of the shape of the utility function, we estimate a logistic regression that relates asset investment strategy $(0=$ invests in all assets; $1=$ invests in assets only traded on exchanges) to group-membership (EXP versus IPT function), controlling for the size of the managers' portfolio, age, education and debt-to-asset ratio.

Table 4 provides the results of the logistic regression. The statistical results indicate a good fit with a Nagelkerke $R^{2}$ of 0.39 , which is relatively high for cross-sectional data, and the model correctly classifying $76.9 \%$ of the investment strategies. More importantly, the coefficient of the shape of the function was significant $(p=0.04)$ while the other variables included in the model (debt-to-asset ratio and value of portfolio) were not.

The results show that managers with an Sshaped utility function choose an asset allocation strategy that consists of exchange traded assets only. Managers with an S-shaped utility function perceive risk from gains and losses (as reflected by the point of inflection of their utility function) differently, a contrast that may heighten their awareness and need to rapidly assess opportunities for profit and prospects of losses. This structure is highly congruent with trading assets on exchanges where price quotes are readily available and traders continuously think about their portfolio in terms of gains and losses (e.g. Abbas et al., 2007). In contrast, managers with a fully concave or convex utility function may invest based on their overall risk attitude (which does not change over the outcome range) and be less concerned with costs and opportunities of immediacy in the market. Adding non-exchange traded assets such as property to their bonds and stocks reflects a straightforward desire to diversify their optimal portfolio risk exposure.

Organizational theory has shown that the environment in which managers operate influences 
the weight attached to their decision criteria (Aldrich, 1979; Rajagopalan et al., 1993). In a strategic asset allocation context, the firm's liability structure (e.g. future financial obligations) is a relevant aspect of its internal environment. Here, managers of firms with known future financial obligations may focus on how their portfolio yield will meet these financial obligations. The unidimensional focus on the responsibility of these obligations may result in utility functions that do not have a point of inflection (e.g. S-Shaped utility function), reflecting that they have risk preferences that do not change over the outcome range, and in portfolios that include bricks and mortar. To investigate this we examined the shape of utility functions of managers who work for firms that have known future liabilities (insurance and pension fund companies).

Table 5 shows that $63 \%$ of the firms with future financial obligations have fully concave/convex utility function and hence include bricks and mortar to their portfolios. In contrast, only $38.5 \%$ of the firms that do not have known financial future obligations exhibit fully concave/ convex utility functions (e.g. 61.5\% exhibit Sshaped utility functions). A $\chi^{s}$ test showed that these differences are significant $(p<0.001)$. These results suggest that the environment in which managers operate influences the shape of the utility function which is played out in different strategic decisions.

\section{DISCUSSION AND CONCLUSIONS}

Here we examine whether the shape rather than the curvature of the utility function contains information that helps predict strategic behavior. We extend previous work by analyzing strategic behavior because of the seemingly natural correspondence between the shape of the utility function and the nature of strategic decisions. The results show that the shape of utility function differs among decision makers and that the heterogeneity is played out in different strategic decisions. This result confirms and extends the findings of Pennings and Smidts (2003) who demonstrated that the shape of the function can help to predict organizational behavior-the decision of which production system to employ. Similar to strategic behavior, organizational behavior is arguably a step beyond operational decision making, and considers the entire range of enterprise decisions. In this context, the results support the notion that identifying the global shape of the utility function that impounds various facets of decision-maker's utility can be useful for understanding multiple dimensions of higherorder behavior. Our results suggest that the environment in which managers operate may play a role in shaping the shape of the decision-makers' utility function.

The presence and the implications of this differential effect for understanding behavior need further investigation and development. One aspect that immediately emerges is the need to study the effects of different functional forms. Here, we only examined two widely used classes of shapes: fully concave/ convex and S-shaped. Often these shapes are implicitly assumed, without actually examining the shape of the utility function. Other functional forms may exist and future research may focus on the information they provide about individual behavior.

In light of the emerging evidence that the overall shape of the utility function influences observed behavior, further work that systematically relates the shape of the utility function to strategic behavior in various situations is needed. Such an agenda may permit a deeper understanding of managerial behavior and performance, and possibly allow us to identify factors that determine the shape of the utility function, which remains an unexplored area of research.

\section{APPENDIX A FUNCTION SPECIFICATIONS}

EXP function: $U(x)=a+b \operatorname{EXP}(-c x)$.

IPT function: $U(x)=1 /(1+\operatorname{EXP}[-\alpha-\beta(1 / \kappa) \log$ $(1+\kappa x)])$.

\section{Acknowledgements}

The authors are grateful for the generous participation of the 104 portfolio managers in the experiments and the companies providing accounting data. Financial support provided by 'de Algemene Stichting Termijnhandel' (AST), NYSE-Euronext, the Chicago Mercantile Exchange, the Niels Stensen Foundation, Office for Futures and Options Research and the Foundation for Research in Derivatives is gratefully acknowledged. The authors thank seminar participants at INSEAD, Iowa State University, London Business School, Rotterdam School of Management, Erasmus Graduate School of Business, Syracuse University, Tilburg University, UC Berkeley, UC Los Angeles, University of Illinois at Urbana-Champaign and 
Wageningen University in The Netherlands for their comments. We are grateful for the conversations we had with Thieu Meulenberg, Don Kleinmuntz and Ale Smidts about this research. This research has been screened to ensure that no confidential data are revealed. The authors express thanks to the Editor and an anonymous referee who provided helpful comments on preliminary versions of the manuscript.

\section{REFERENCES}

Abbas AE, Matheson JE, Bordley RF. 2007. Effective utility functions from target-based incentives. Working paper, University of Illinois at Urbana-Champaign.

Aldrich HE. 1979. Organizations and Environments. Prentice-Hall: Englewood Cliffs, NJ.

Ansoff HI. 1965. Corporate Strategy: An Analytic Approach to Business Policy for Growth and Expansion. McGraw-Hill Inc.: New York (revised 1987).

Arrow KJ. 1971. Essays in the Theory of Risk Bearing. Markham: Chicago.

Bell DE, Fishburn PC. 2000. Utility functions for wealth. Journal of Risk and Uncertainty 2(1): 5-44.

Bewley R, Fiebig DG. 1988. A flexible logistic growth model with applications in telecommunications. International Journal of Forecasting 4(2): 177-192.

Binswanger HP. 1981. Attitudes toward risk: theoretical implications of an experiment in rural India. Economic Journal 91(364): 867-890.

Binswanger HP. 1982. Empirical estimation and use of risk preferences: discussion. American Journal of Agricultural Economics 64(2): 391-393.

Budescu DV, Weiss W. 1987. Reflection of transitive and intransitive preferences: a test of prospect theory. Organizational Behavior and Human Decision Processes 39(2): 184-202.

Eisenhardt KM, Zbaracki MJ. 1992. Strategic decision making. Strategic Management Journal 13(1): 17-37.

Farquhar PH. 1984. Utility assessment methods. Management Science 30(11): 1283-1300.

Fischer GW, Carmon Z, Ariely D, Zauberman G. 1999. Goal-based construction of preferences: task goals and the prominence effect. Management Science 45(8): 1057-1075.

Fishburn PC, Kochenberger GA. 1979. Two-piece Von Neumann-Morgenstern utility functions. Decision Sciences 10(4): 503-518.

Harrison G. 1986. Risk aversion and preference distortion in deterministic bargaining experiments. Economics Letters 22(1): 191-196.

Hershey JC, Kunreuther HC, Schoemaker PJH. 1982. Sources of bias in assessment procedures for utility functions. Management Science 28(8): 936-954.

Holt CA, Laury SK. 2002. Risk aversion and incentive effects. American Economic Review 92(5): 1644-1655.

Kagel JH, Roth AE. 1995. The Handbook of Experimental Economics. Princeton University Press: Princeton, NJ.
Kahneman D, Tversky A. 1979. Prospect theory: an analysis of decision under risk. Econometrica 47(2): 263-291.

Keeney RL, Raiffa H. 1979. Decisions with Multiple Objectives: Preferences and Value Tradeoffs. Wiley: New York.

Kuhberger A, Schulte-Mecklenbeck M, Perner J. 1999. The effects of framing, reflection, probability, and payoff on risk preference in choice tasks. Organizational Behavior and Human Decision Processes 78(3): 204-231.

LiCalzi M, Sorato A. 2006. The Pearson system of utility functions. European Journal of Operational Research 172(2): 560-573.

Meade N, Islam T. 1995. Forecasting with growth curves: an empirical comparison. International Journal of Forecasting 11(2): 199-215.

Pennings JME, Smidts A. 2000. The shape of utility functions and organizational behaviour. Management Science 49(9): 1251-1263.

Pennings JME, Smidts A. 2003. The shape of utility functions and organizational behavior. Management Science 49(9): 1251-1263.

Pratt JW. 1964. Risk aversion in the small and in the large. Econometrica 32(1): 122-136.

Quinn JB, Mintzberg H, James RM. 1988. The Strategy Process: Concepts, Contexts, and Cases. Prentice Hall: Englewood Cliffs, NJ.

Rabin M. 2000. Risk aversion and expected-utility theory: a calibration theorem. Econometrica $\mathbf{6 8}(5)$ : 1281-1292.

Rajagopalan N, Rasheed AMA, Datta DK. 1993. Strategic decision processes: critical review and future directions. Journal of Management 19(2): 349-384.

Schoemaker PJH. 1982. The expected utility model: its variants, purposes, evidence and limitations. Journal of Economic Literature 20(2): 529-563.

Smidts A. 1997. The relationship between risk attitude and strength of preference: a test of intrinsic risk attitude. Management Science 43(3): 357-370.

Smith VL. 1991. Rational choice: the contrast between economics and psychology. Journal of Political Economy 99(4): 877-897.

Swenk CR. 1995. Strategic decision making. Journal of Management 21(3):471-493.

Trepel C, Fox CR, Poldrack RA. 2005. Prospect theory on the brain? Toward a cognitive neuroscience of decision under risk. Cognitive Brain Research 23(1): 34-50.

Tsiang SC. 1972. The rationale of the mean-standard deviation analysis, skewness preference and demand for money. American Economic Review 62(3): 354-371.

Tversky A, Sattath S, Slovic P. 1988. Contingent weighting in judgment and choice. Psychological Review 95(3): 371-384. 